\title{
Abuse through sexual image sharing in schools: Response and responsibility
}

\begin{abstract}
The question of how to tackle abuse through adolescent sexual image sharing is an increasing concern for schools, yet little is known about how they should respond. In this article, I review school responses to this phenomenon. The findings presented are taken from a mixed-methods study into harmful sexual behaviour carried out in seven educational settings across four local authorities in England. Using data from focus groups, observations, case reviews and reviews of policies and procedures I present findings on abuse through image sharing including suggestions for safer school environments.
\end{abstract}

I argue that responses to adolescent sexting must move beyond risk aversion and challenge the very socio-cultural systems that enable abuse through sexual image sharing. Achieving this requires responses that recognise developing adolescent sexuality within a digital age and understanding what works in practice for schools and young people. Concurrently, schools have responsibility to challenge socio-cultural norms underlying harmful sexual practices between young people.

Keywords: sexting; schools; revenge porn; contextual safeguarding; harmful sexual behaviour

'To humiliate them' he said. 'It's almost worse than beating someone up. You can heal from a fight but a photo is always there ${ }^{1}$ - One boy explains why students share sexual images without consent. It’s about power.

In schools across the UK and internationally students share sexual photos of young people without consent as a way to shame and degrade (Ringrose et al. 2013). This boy's answer encapsulates the fear and anxiety many parents, teachers and policy makers feel about sharing sexual images online - that they will be used as a weapon and they are permanent (Dobson

\footnotetext{
${ }^{1}$ Extract from focus group with boys.
} 
and Ringrose 2016). Yet within a digital era mobile technology is part of how many young people learn about sex, and develop sexually (Cooper et al. 2016). And while abuse through image sharing represents a minority of the total instances of adolescent sexual image sharing (Wolak and Finkelhor 2011, Steeves 2014), the significance and implications of this form of abuse requires intervention. One place where non-consensual image sharing - sometimes referred to as revenge porn (Stroud 2014) - can have a particularly negative impact is schools (Van Ouytsel, Walrave, and Van Gool 2014, Branch et al. 2017). In this article, I explore school responses to abuse through image sharing in light of social, cultural, policy and legal frameworks.

Rapid advancements in technology, surpassing the evolution of legislation means the law is not always equipped to keep up with how young people use mobile technology (Williams 2011). In the UK, it is illegal for any person under 18 to take, possess or share an explicit photo of themselves or another person under 18 (Sexual Offences Act 2003). At the same time, many professionals including the police, emphasise the need for proportionate responses handled as safeguarding, rather than criminal, concerns when sharing occurs (NPCC 2016). To categorise all sexual image sharing as illegal but suggest practitioners should not criminalise young people makes responding to the abusive forms of image sharing a challenge. Photos do not inherently possess the power to humiliate, but the environments in which they are shared can work to empower them. By considering the extent to which this happens in schools, I argue that schools must develop responses to sexual image sharing but also have responsibility for creating safer school environments.

\section{Understanding adolescent sexual image sharing}

To explore school responses to abuse through sexual image sharing I differentiate between consensual image sharing, and abuse through image sharing (Simpson 2013). Consensual 
image sharing denotes sharing within the context of a non-exploitative relationship (regardless of the legal age of consent) (Karaian and Van Meyl 2015). Abuse through image sharing includes what Willard (2010) describes as exploitative sexting: demanding an image in an abusive relationship; revengeful distribution following a break-up; using an image to blackmail a person; and abusive acquisition intending wider distribution. I use the term sexting and image sharing to refer to sexual images produced and shared by young people consensually. ${ }^{2}$ At times, participants refer to abuse through image sharing as 'sexting'. I begin by considering the legal and policy landscape before moving into research in this area.

\section{The law and guidance}

In recognition of the challenge schools face in responding to sexual image sharing, the UK Council for Child Internet Safety (2016) have developed guidance for schools to supplement statutory guidance on Keeping Children Safe in Education (Department for Education 2018). The guidance outlines one piece of legislation in relation to sexting, the Sexual Offences Act 2000, which states:

- It is an offence to possess, distribute, show and make indecent images of children.

- The Act defines a child, for the purposes of indecent images, as anyone under the age of 18

Consequently, both consensual and non-consensual adolescent image sharing is prescribed as illegal (Calvert 2009). The emphasis within this guidance to particular legislation, where both production and sharing are equally emphasised, implicates how schools understand and educate young people about the law (UKCCIS 2016), resulting in education to students that equally prioritises prevention of consensual and non-consensual image sharing (UKCCIS 2016).

\footnotetext{
${ }^{2}$ Sexting was often referred to as ‘sending nudes’ by young people.
} 
Several other laws do exist in relation to sexting, including legislation that addresses the revengeful distribution of sexual imagery (O'Connor et al. 2017). This includes the Communications Act 2003 and the Criminal Justice and Courts Act 2015 which states:

- It is an offence for a person to disclose a private sexual photograph or film if the disclosure is made- (a) without the consent of an individual who appears in the photograph or film, and (b) with the intention of causing that individual distress

This legislation is not outlined in the UKCCIS guidance to schools. While the guidance does differentiate between consensual and revengeful image sharing little is known about what this looks like in practice within schools. The guidance states:

If a young person has shared imagery consensually, such as when in a romantic relationship, or as a joke, and there is no intended malice, it is usually appropriate for the school to manage the incident directly. In contrast any incidents with aggravating factors, for example, a young person sharing someone else’s imagery without consent and with malicious intent, should generally be referred to police and/or children’s social care. (emphasis added). (UKCCIS, 2016, 12)

The prominence of the Sexual Offences Act as the key legislative framework for addressing sexting in this guidance, and the invisibility of legislation related to non-consensual image sharing, highlights the prioritisation of risk-averse approaches to adolescent image sharing.

The broad-brush application of legislation intended to be used to prevent adult production and sharing of child pornography, to children, raises significant challenges for professionals. As Albury and Crawford (2012) note, the disparity between the age of sexual consent (16) and consent to sharing images (18) ignores young people's agency and their own perceptions of development. And while police guidance suggests sexting responses should be 
'proportionate' (NPCC 2016), this may do little to minimise professional anxiety on how to respond (Draper 2012). While a distinction is made between consensual and non-consensual image sharing, the challenge of managing incidents directly is significant when there is limited guidance on what interventions are tried and tested, and when all sexual image sharing is defined as illegal.

\section{Research and practice perspectives}

Researchers have sought to identify the prevalence of young people sharing sexual images, both consensually and non-consensually (Phippen 2009). Yet, harder to determine, is the predominance of abuse through sexual image sharing. The National Campaign to Prevent Teen and Unplanned Pregnancy (2008) found that 33\% of teen boys and 25\% of teen girls had received a sexual image of another person without the person in the image's consent (Chalfen 2009). Wolak and Finkelhor's (2011) data suggests that in 15\% of cases a sexual image intended to be shared with one recipient was shared with others (Quayle and Cooper 2015). Reviewing several studies, Willard (2010) found boys and girls equally participate in image sharing but girls feel more pressure to do so. Englander (2012) found that girls were twice as likely as boys to be coerced into sharing an image. Beyond prevalence studies, research has explored sexual image sharing from a range of perspectives including the impact, risks and gendered nature of abusive sharing, and sharing within the context of agency and sexual development, as is explored below.

\section{'Risky’ practices}

The dominant approach to sexual image sharing in policy and practice has largely focused on it as a risky practice increasing the sexualisation of children (Salter, Crofts, and Lee 2012). Döring (2014) found 79\% of papers they reviewed explored adolescent sexting as a risky behaviour. Research within this discourse often link sexual image sharing to negative 
consequences, for example citing tragic cases that have resulted in suicide (Crimmins and Seigfried-Spellar 2014). Links are drawn between sexting and a range of risks, including psychological difficulties (Smith, Thompson, and Davidson 2014), , depression (Van Ouytsel et al. 2014) and ‘risky’ sexual behaviour (Temple and Lu 2018).

The legal implications of sexting are also emphasised, including the risk of being registered on the sex offenders register (Gross 2017) and the legal challenges arising from the use of child pornography legislation (Holoyda et al. 2018). In popular discourse, media articles have focused upon the risks young people may face of imprisonment for consensually sharing images (Paul 2017). Risk averse approaches to sexting can be seen to implicate how some practitioners tackle sexting (Draper 2012). As Karaian and Van Meyl (2015) note, this work can at times fail to distinguish between consensual and non-consensual image sharing. Although in the UK practitioners prioritise non-criminal methods of working, rather than punitive sanctions to manage sharing explicit images between young people (Moran-Ellis 2011), in practice emphasis is on encouraging abstinence from sending images with a reminder that such practices are illegal (Döring 2014).

\section{Gendered discourses}

Other research has emphasised the gendered nature of coercive and harmful sharing. This work highlights the implications of education focussed on telling young people not to send images in the first place (ThinkUKnow 2011). Scholars from this perspective suggest, that risk-aversion strategies that consider all image-sharing, including consensual sharing, as a problem can characterise the sender as both a victim yet simultaneously responsible for their behaviour (Angelides 2013). As Dobson and Ringrose (2016) demonstrate, this can unevenly target girls, who receive judgement, harassment and shame whereas boys are seen as 
demonstrating hegemonic masculinity (Harvey and Ringrose 2015). They suggest this represents a sexual double standard: where boys gain cultural capital by capturing evidence of girls’ bodies whereas girls get shamed for sending the images (Harvey and Ringrose 2015, Ringrose et al. 2013). Ringrose et al. (2013, 307) highlight how: ‘discourses of “sexting” risk thus reproduce moral norms about sexual subjects, constructing girls' sexuality as a particular problem to be surveilled and regulated'. How young people use technology is important. The ephemeral nature of some media platforms allows young people to maintain some control over who and when an image is shared (Charteris, Gregory, and Masters 2016). At the same time, the ability for users to capture and save images - for example through screen shots allows young people to gain recognition for receiving images of bodies and to shame those in the images.

\section{Sexual agency and development}

Dominant social, cultural and legal discourse shape discussions of adolescent sexting by adults. Other discourses offer an alternative approach by exploring image sharing in relation to young people’s agency and sexual development (Dobson and Ringrose 2016). While media 'panic' can bolster the assumption that sexting is always problematic, Levine (2013) asks why research and practice starts by linking it to unhealthy behaviour. Approaches from this perspective ask practitioners to consider (some) image sharing as a consensual act and form of sexual expression. Hasinoff (2013) echoes this, arguing if practitioners viewed creating images as media production this would help distinguish between consensual and non-consensual image sharing. This would allow us to account for power dynamics at play, providing clearer routes for supporting and tackling harmful practices.

These approaches demonstrate the need to explore the reasons young people send images, what happens and how they feel about this. As Chalfen (2009) notes, few studies actually 
explore sexting when no harm is caused. It therefore is important to consider how sexting fits within young people’s everyday lives. Rather than extraordinary, by looking at sexting through the intersection of media, technology, visual and adolescent cultures would provide a framework for understanding the contexts in which young people engage in different forms of communication (Ibid, 2009). By considering children as autonomous and empowered individuals, and sharing images as part of their sexual development within a digital age, children can be seen to challenge traditional notions of childhood and innocence (Simpson 2013). Karaian and Van Meyl (2015) suggest that existing approaches to sexting conflate both-consensual and non-consensual image sharing denouncing the possibility of consensual and safe sexting. They argue that instead, researchers and educators must pursue alternative frameworks and discourses, such as queer theories, to acknowledge young people's right to sexual expression. Considering that evidence suggests the majority of sexual images shared consensually are never shared beyond the intended receiver (Steeves 2014), educational programmes must progress beyond risk aversion, to consider adolescent sexuality in a new and changing digital era.

To focus on abuse through sexual image sharing I situate school responses within literature on risk aversion, gender discourses and young people’s agency. Within the context of schools, I question the structures in place normalising and capitalising on the creation and sharing of images of girls' bodies (Ringrose et al. 2013). When schools promote abstinence, the school environment becomes one that polices (girls') bodies by perpetuating narratives that shame young people if they breach the rules. We know abuse through image sharing happens in schools between students but we know very little about the responses schools use to tackle this. I begin by outlining the methodology and research approach used. 


\section{Methodology}

The findings presented here come from a broader research study into harmful sexual behaviour (HSB) in schools. Using a mixed-methods approach the research aimed to:

- Identify multi-agency enablers and barriers to preventing and responding to HSB in schools.

- Develop tools and resources for inspectorates, schools and multi-agency partnerships to self-assess current responses to HSB.

While the project did not seek to focus on any specific forms of HSB, abuse through sexual image sharing emerged as a consistent theme throughout the research and subsequent analysis. For the purpose of the research HSB was defined using Hackett’s (2010) continuum of sexual behaviours. This spectrum helps practitioners understand young people's sexual behaviours and what is developmentally expected for their age. As such, the research, and this paper, focusses specifically on abuse through image sharing, as opposed to the spectrum of sexting behaviours young people may engage.

Rather than viewing HSB as isolated incidents experienced or carried out by individuals, the research team utilised a contextual safeguarding model to broaden understanding of how harm manifests in different social fields - of which the school is one (Firmin 2017a). Firmin’s contextual safeguarding model supported us to develop methodologies to interrogate how harm manifests in schools and a framework to analyse the findings. Firmin (2017b) argues child protection responses often individualise experiences of abuse.

Contextual safeguarding helps consider abuse, for example abuse through image sharing, in the context it occurs, recognising young people's agency as shaped by social contexts and part of gendered ideas reinforcing or challenging harm. Contextual safeguarding moves 
beyond looking at the individual - who sent the text and why - to broader appreciation of the systems and structures contributing to it being harmful - why can sharing an image humiliate?

\section{Sample and methods}

We used a mixed-methods approach in four local authorities across England, referred to throughout as sites. Following previous research carried out by the research team, we recognised that understanding responses to HSB in schools requires exploring both school responses and how local authorities support schools. Therefore, we carried out research in both schools and the multi-agency partnership. The seven schools involved sit within the geographical jurisdiction of three of the four local authorities where we carried out the research. The research methods involved:

\section{Schools}

- 17 focus groups with young people

- 12 focus groups with school staff

- 9 observations in schools

- 8 reviews of behaviour incident logs within schools

- Reviews of policies and procedures

\section{Multi-agency partnership}

- 4 focus groups with multi-agency practitioners

- 16 observations of multi-agency meetings relating to HSB

- 3 case reviews of incidents of HSB

- Reviews of policies and procedures

While I use the term schools throughout, the research took place in a variety of educational provisions including: 16-18 provision ( $\mathrm{n}=2$ ), pupil-referral units for young people excluded from mainstream education ( $n=2)$, split-site provision $(n=2)$, further education colleges $(n=2)$, faith-based school $(n=1)$, majority-male $(n=3)$, secular schools $(n=6)$, high-schools with sixth-form ( $n=2)$ and special educational provisions $(n=1)$. While the research was carried out in seven schools we completed research in nine school locations due to split-provision and off-site alternative providers. 
The research team used a range of research methods at both the multi-agency and school level that were complimentary in design. These consisted of:

- Observations in schools included before, after and throughout the school day to understand the relationship between the physical environment and young people’s experiences of safety and harm. In the multi-agency partnership meetings relating to HSB were observed, notes evidenced the nature of discussions and actions developed.

- Case reviews in schools involved reviewing behaviour incident and safeguarding logs to ascertain the types of HSB recorded, language used and actions taken. In the partnership a contextual case review methodology (Firmin 2017b) was used to review incidents of HSB in schools, the actions taken and the relationship between the school and external agencies.

- Policies and procedures relating to HSB were reviewed in the partnership and school to consider synergy between responses and the thresholds and interventions outlined for different forms of harm.

- Focus groups were held within the schools and the partnership to identify student and practitioner perceptions of the types of HSB happening, responses engaged, and to further elicit detail from observations and case reviews.

\section{Focus group participants}

In total 142 people were engaged to participate in 33 focus groups. Table One outlines the gender breakdown of the focus group participants. The age of the young people engaged ranged from 13-21 with a mean age of 14.9. While specific information relating to the roles of school staff was not collected, over three quarters of staff were engaged in teaching. 


\begin{tabular}{|l|l|l|l|l|}
\hline & $\begin{array}{l}\text { Number of focus } \\
\text { groups }\end{array}$ & $\begin{array}{l}\text { Total } \\
\text { participants per } \\
\text { group- female }\end{array}$ & $\begin{array}{l}\text { Total } \\
\text { participants per } \\
\text { group- male }\end{array}$ & $\begin{array}{l}\text { Total number of } \\
\text { participants }\end{array}$ \\
\hline Young people & 17 & 26 & 33 & 59 \\
\hline School staff & 12 & 36 & 22 & 58 \\
\hline Multi-agency & 4 & 19 & 6 & 25 \\
\hline Total & 33 & 81 & 61 & 142 \\
\hline
\end{tabular}

Table one: focus group breakdown

Participants were recruited through individual gatekeepers within the schools - either the head of safeguarding or a member of the leadership team. For the young people's focus group, the school lead selected and approached individual young people to gain their consent to participate. For the staff focus groups individual staff were either approached directly or provided with information about the study via email and were able to sign-up to participate themselves. Within the multi-agency focus groups the single point of contact for each site recruited participants for each focus group from a range of agencies including the police, social care, voluntary sector, education and health. While we outlined to schools that we were looking to speak to a range of students, in terms of behaviour, communication skills, needs, age and gender, as the school recruited participants, and data was not recorded on these issues, it is not possible to determine how diverse the sample was.

This study received ethical approval from the University of Bedfordshire in addition to approval from the four participating Local Safeguarding Children’s Boards. Considering the sensitive nature of the study it was essential to account for the implications of research on the participants involved. Such considerations included consent, confidentiality, pathways for safeguarding concerns, security, data storage and ensuring confidentiality. In particular, the research team developed mechanisms to deal with disclosure (although no such instances arose). To ensure anonymity all names have been changed. 


\title{
Findings
}

I explore findings in relation to three areas. I begin with ways abusive sharing occurred within schools, secondly, schools responses to these issues. Finally, I suggest opportunities to create safer school environments.

\section{Abuse through image sharing in schools}

Participants spoke about consensual or non-consensual image sharing in every focus group. Young people only discussed abuse through image sharing, whereas staff and practitioners discussed both consensual sharing and abuse through image sharing. The following two extracts demonstrate some exploitative ways images were shared within schools:

\author{
Interviewer: [what types of HSB are you seeing?] \\ David: Sexting as well, so inappropriate pictures/videos being shared. \\ Marika: Yeah, that as well. Sorry. We'll get referrals for kids that are so distressed \\ because they've sent a picture of themselves to someone and then they feel so bad about \\ it and then it's caused all sorts of anxiety and other stuff. They don't even want to go back \\ to school. (Multi-agency focus group 1)
}

Anita: Photos being sent around and shared, there's quite a bit of that when the relationship is over. (Multi-agency focus group 2)

The quotes above, and the majority of discussions, suggest sexting itself is not the problem but the fear, or experience of, having the image shared beyond the perceived receiver. This distinction is important when we consider abuse through image sharing and how schools can respond.

\footnotetext{
Abuse through image sharing happened in all schools we visited as evidenced in focus groups and case reviews. Typically, this involved a girl’s image being shared on social media without her consent. This could be through someone directly sharing the image with their
} 
friends, social media 'followers’ or anonymously. Social media platforms used varied between incidents but the intent of sharing was similar across incidents - for people to see. In the following discussion, a group explain ways images are shared in their school through 'bait out' pages. These provide a more anonymous way of sharing images: ${ }^{3}$

Joe: There are bait out pages - the tagline says 'send us nudes you want to bait out'. It's usually on Instagram. They usually get blocked. They ask 'shout us out to share our page'. Mostly done by people who don’t like them (the person they share the picture of). $[\ldots]$

Interviewer: What's the point of these pages?

Joe: Humiliation. It’s almost worse than beating someone up. You can heal from a fight but a photo is always there. It says how to find her because they tag them.

Interviewer:Is it always girls?

Ajay: I've never seen a boy getting baited out. Boys don't send them as much. A girl is less likely to put it up (share it) will just show it to friends. (High School 1, boy's focus group) $)^{4}$

Although 'bait out' pages allow a certain amount of anonymity participants suggested remaining anonymous was not necessarily always important. Some media platforms allow young people to share images without naming them, by using a pseudonym or via a proxy page. The benefits mean teachers may not be able to gather evidence of who shared the image. However, there are also benefits of publicly sharing an image by using your own named social media account. As Harvey and Ringrose (2015) have documented, wider image distribution is a crucial aspect for gaining peer recognition and cultural capital for receiving the image from someone in the first place and is essential to demonstrating hegemonic masculinity to peers (Harvey and Ringrose 2015). 'Tagging' an image provides a further way to ensure someone is humiliated and shamed by peers, as these young people suggest, by allowing people to “find her”. Tagging presents particular challenges; reducing a person’s

\footnotetext{
${ }^{3}$ There are other non-harmful uses of bait out pages

${ }^{4}$ The extract is a summary of the conversation with verbatim quotes as written notes were taken at the group’s request.
} 
agency and ability to control images and acting as a reminder of the supposed transgression (Barbovschi and Velicu 2015). If, as the majority of students we spoke with suggested, there are limited responses from schools to these incidents, the benefits of publicly sharing an image - the cultural capital - outweigh the disadvantages of school punishments. So how are schools responding?

\section{School responses}

School responses to abuse through image sharing varied significantly between schools and incidents. Depending on the severity, we found wide-ranging responses, from: students having their phones removed and being given detention, being excluded or placed in isolation, to referral to police. Students also reported another response by many schools inaction. The summary below comes from an observation at a Fair Access Panel (FAP) and outlines some variations in responses by schools. The FAP is a meeting held between schools in a local authority aimed at finding placements for students who have been excluded or to manage student moves between schools. Here FAP attendees are talking about image sharing within schools and the varied responses:

Janet: We have had similar issues with indecent images in school but they have been managed within school rather than excluding for instance. We just don't allow him to have a phone.

Modi: Image sharing is becoming a live issue for all schools.

[Discussion of a case where a school had permanently excluded a student for sending a sexual image]

Claire: We need to discuss the level of threshold for permanent exclusion for sending sexual images. Half our year nine students would go if this was our policy. (Observation of Fair Access Panel 2)

In the absence of robust guidance on how to 'manage incidents directly', schools develop their own responses to abuse through image sharing. This discussion appears to relate to 
responding to non-consensual image sharing. Claire’s comment suggests high sexting instances in her school. Yet, it is not clear if she refers to sexting in general or the wider nonconsensual image distribution, furthermore how they respond if they do not exclude. Clearly, schools feel unsure how to respond, and what the threshold for exclusion should be.

Ultimately, all schools suggested they felt unable to respond to HSB incidents occurring online. The variation in responses and at times inaction by schools meant students often perceived schools doing nothing so assumed schools could do little to tackle the issue:

Amal: In terms of the root of it, I don't think the college can do much about the online stuff, they can't control what people do outside college, they can only control what happens in here. So even so, they can tame what happens here, maybe a student will get suspended for a couple of days, but it still happens (College 1, girl’s focus group)

All students and teachers appeared resigned to the fact that image sharing (both consensual and non-consensual) was inevitable and there was very little schools could do to prevent this. Firstly, because students felt schools do not have jurisdiction to penalise students for things outside school and secondly, because sanctions - such as suspension- were ineffective. The majority of discussions centred on preventing image sharing rather than changing the context where sharing happens.

Students and practitioners felt there were few consistent or effective responses available for tackling the spectrum of sexting behaviours. This is compounded by the fact that the law surrounding sexting is not suitable for responding to the different ways young people share images. Not only does the difference between the law and guidance mean staff often become unable to differentiate harmful from normal sharing practices, this anxiety by staff impacts how young people view it. 
Rahul: One of the biggest problems with the texting, sexting in school is the scope, so what is kind of normal, okay, usual and what crosses over and what's not okay? And kids eternally do not get it, they don't understand and they don’t understand even when we've sat in front of them, that they've actually done something wrong so that behaviour is quite normal to them, they don't understand that they've crossed any kind of boundaries and especially if it's been consensual on both sides but they’ve been caught. (Multi-agency focus group 4)

It is not surprising students do not know what is okay if practitioners themselves do not know 'normal' practices from 'what's not okay'. Clearly, practitioners have awareness of a spectrum of behaviours but suggest all sharing, even consensual, is 'wrong'. I do not want to normalise harmful behaviour but rather highlight the importance of understanding sexting within the context of developing adolescent sexuality within a digital age. Furthermore, treating all sharing as wrong reduces the likelihood students will seek help in harmful incidences and perpetuates a victim-blame culture that obscures the attention of who to blame in these instances.

Two issues arise here: what the law defines as illegal and what adults and young people consider harmful. Uncertainty results in lack of confidence by staff in how to respond.

Mark: Staff are not very confident to tell this is within the normal range or a potentially harmful range. Sometimes I think there's just a whole lot of denial going around what's happening and everyone experiencing [lack of] confidence, teachers, practitioners, staff and parents.(Multi-agency focus group 1)

Image sharing includes a spectrum of behaviours. Hackett's (2010) continuum provides a helpful tool to understand where individual behaviour falls. However, there are two problems. Firstly, the law defines all image sharing on the spectrum as illegal. Secondly, this only provides a framework for looking at individual behaviour rather than the socio-cultural 
context those behaviours occur in. This limits our attention to young people sending and receiving messages rather than, more importantly, the broader social fields in which behaviour becomes normalised and abusive. There are many barriers to how schools respond. For example: the complexities in determining if messages are harmful, the sheer volume of image sharing (both consensual and non-consensual), lack of training or knowledge of how apps and technology work by staff, limited understanding of what responses work in practice and anxiety surrounding concern for criminalising young people. In many instances these barriers resulted in a similar response across schools - inaction.

\section{Inaction and its consequences}

There are multiple factors to consider when assessing how schools respond to HSB. The findings suggested that the schools did not know how to respond to incidents of abuse through image sharing; resulting in inaction to abuse in some cases and knee-jerk reactions to consensual sharing in others. This has significant implications to how students perceive nonconsensual sharing of images and schools' ability to protect them and make safer environments. To be clear, while schools may respond to incidents (and sometimes they did not), students did not always see responses taking place. Take for example the following two accounts from a focus group with staff and students in the same college. It is not clear if they are talking about the same incident as the staff noted they had several incidents:

Marie: A number of students were interviewed and statements taken and stuff like that. But there wasn't any clear evidence, so I think possibly online things, when people have got numerous [online] accounts and stuff like that, it's quite difficult for us to deal with. Theo: I mean that's a legal forensic type of investigation.

Paul: Yeah, but it was referred to the Cyber Criminal Unit.

Marie: Yeah, I understand, but from the point of view of the victim, frustration and nothing seemed to be done. So, from his point of view reporting it or... I don't know, but I think there's a failing there definitely. (College 1, staff focus group) 
Billy: But with the whole incident of my friend and the fake Instagram, nothing was done to those people and they had sexually explicit photos of an under 18 and nothing happened to them. Maybe I'm just biased because I think they should be ... But yeah nothing much happened and my friend's just basically accepted that. I don't think he should.

Interviewer:Ideally what would you have liked to have seen happen from that? Billy: Like a police investigation, because I know police did come in. Or like for them to be treated like anyone being treated if they had underage nudes on their phone. Or even to be expelled because of the cyber bullying.

Interviewer:So, what happens to people that have nudes on their phone, or that are cyber bullying?

Billy: Apparently nothing. Well there was a police investigation, but nothing else happened.

Interviewer:Since after that event, was there anything done in the school in the college? Any kind of discussions around the issues or cyber bullying?

Billy: No, it was basically kept quiet. (College 1, boy’s focus group).

The fact students perceive no interventions taking place is important. No one has been punished and no changes have been made. The student's knowledge of the law augments this confusion. The suggestion that limited sanctions exist for abuse through image sharing was made in the majority of schools:

Dean: There is no punishment for these things. For sexting they just take photos down I don’t think anything else happens. (Pupil referral unit 4, boy’s focus group)

There are implications to inaction. When students perceive no interventions taking place school inaction normalises the idea abuse is accepted. Students and staff suggested this reduces the likelihood young people will speak out when they see or experience harm and further erodes staff confidence and experience in how to respond. Clearly, schools must respond in ways that supports those involved, the wider school environment and adheres to their legal duties. Inaction can in many cases, shape young people's own perceptions of what is acceptable or harmful behaviour within their own school. 
When students were asked what could be done to prevent non-consensual image sharing, the majority of responses focussed on not sharing it in the first place - echoing much of the guidance and education young people receive on sexting in the UK (Think U Know 2017). They also highlighted their perception that there was very little schools could do:

Interviewer:What could be done to prevent this in the first place?

Emma: Don't send the photo in the first place.

Dee: There's no way to stop it being shared.

Emma: Even if people you don’t know see it.

Interviewer: Do the people that share it get in trouble?

Emma: People don't get in trouble.

Dee: A teacher tells them to take it down. They have like five days or they get excluded. Emma: There's no point taking it down if it's out. (Pupil Referral Unit 4, girl’s focus group)

In the absence of visible responses by schools, students develop their own responses to tackling harmful image sharing. During the focus groups we asked young people how a student in their school would respond to different scenarios. In the following situation, I outlined a scenario where a student shares an image of a naked girl around school:

Joe: The mentality of most students is the girl knows it's been leaked she'll tell the teacher so you don't have to.

Jessie: You might think it’s just a joke. But sending nudes isn’t really a joke.

Joe: $\quad$ Some would say something to bring it down but don't want to get involved, you don't know the whole story behind it. She could have done something first. A friend of the girl would tell the girl even though the girl is one being exploited she might get in trouble as her family would be told. (High school 1, boy's focus group)

Multiple issues impact a young person's decision to inform a teacher - from not wanting to get involved to not knowing the full situation. The responsibility for the incident all appears to focus on the girl - from her reporting the incident, potentially being in some way to blame 
for why it was sent, and ultimately the one who will receive the negative impact of having her image shared, and the responses made by schools and her parents. How schools respond and the messaging and education given to young people has significant implications. Education, intervention and sanctions can all alter the way young people themselves understand harm and respond.

\section{Safer school environments}

Dominant messages about sexting - that it is always wrong- have implications for how incidents are viewed and responded to. Comments made by staff and students often echoed dominant narratives surrounding abuse through image sharing - that young people are in some ways responsible. Many students suggested the way to prevent harmful sharing of images was not to send the image in the first place. While staff often questioned why young people take and send naked photo of themselves, no-one questioned why people share images without consent.

There are significant and often contradictory rules at play within school environments. In one sense, these rules motivate young people to send images. In the other, they will police young people if they do. Dobson and Ringrose (2016) highlight how schools are normatively constructed as places that police transgressions of sex and gender rather than places of support. But what if this wasn't the case? Schools may not be able to challenge wider sociocultural systems working to oppress girls and women, facilitating gendered abuse, violence and exploitation. But, schools can create safer social environments within their borders. They can do this by protecting young people, challenging the very systems allowing abuse to happen and changing attitudes and ideas about how young people live their lives safely. Schools can be places for change. We know this because we have already seen this in action. 
When asked about how a student might respond to racist instances young people provided very different answers than to gendered abuse:

Interviewer: But you think there's something obviously working that means that young people have a bit of a zero tolerance for racism?

Bea: Yeah, I don't know what it is, I think it's more just your personal beliefs and there’s so many people that just disagree with racism now, that they'd happily speak up if they were to see it and they'd feel confident enough to do so because I think with racism, you know that you'd get more of a backing behind you if you were to speak up about it whereas yeah, I guess if someone calls someone a slag and that, if you were to say "What are you calling her that for?” or whatever, you don't know if you're going to get much of a backing because not that many people, you don’t know anything about that situation, whereas racism all together is just not great. (College 4, young person focus group)

Racism still happens in schools. Systematic oppression still means young people of colour are disproportionally excluded from classrooms (Krueger 2010). It is not my intention to pit one form of oppression against each other. Instead, I use this example to highlight how work to tackle racism is further along in some respects regarding how young people understand and recognise racism in ways sexism is not. It is a hopeful reminder of how schools can become places that empower young people to challenge oppression.

While difficult to determine the reasons for this distinction, I suggest three possibilities. Firstly, since 2002, following the Race Relations (Amendment) Act 2000, schools in the UK are required to have a written Race Equality Policy in place wherein they have a duty to record and report racist incidents within school to the Local Authority (Gov.uk 2010). No such obligation exists for sexist incidents. This can affect schools’ ability to monitor and respond to racism and inform the ethos of the school. Secondly, this raises questions of how students perceive identity, agency and blame. Students appeared to construct sexual practices and sexuality as a choice, and in relation to sexual image sharing, could be seen to have 
problematic understandings of consent. Consent to produce and send one's own image, was potentially seen to apply to the further sharing of that image or future images. In terms of racism, young people appear to rely on essentialist constructions of race and ethnicity whereby a young person's race is considered to be defined by others and not a choice. As such, young people articulated that they may intervene in harm when they considered the victim to have no choice, as they suggested was the case within racism. This is outlined by one girl during a focus group:

Dee: Racism's worse cos it's your skin colour, you can't help being black it's your skin colour, but you can help being a slag. (Pupil Referral Unit 4, girl’s focus group)

Finally, while young people suggested that they would respond to racist incidents, it is likely that they are referring to overtly racist incidents as opposed to more systematic or subtle forms of racism. Furthermore, intersectional approaches suggest (Crenshaw 1997), it is likely that intersecting identity factors would shape the type of harm and response by young people for different incidents along lines of race, gender, class and ability. Learning from these varied interventions requires further research.

Students did, however, see the double-standard inherent in how young people and staff respond to abuse through image sharing. In the following extract, students have been given a scenario where a girl's image has been shared without their consent and are asked to move across the room from 'do nothing' to 'do something'.

Interviewer:You all moved there with quite a lot of speed, [to do nothing]. Is that because that's just what happens?

Lucy: Because it's your fault for sending it in the first place, you knew that that was going to happen ... 
Donna: The thing is, I don't think that you know that it's going to happen [it being shared further], I just feel like that's the norm these days, you don't do anything about it because they'll just tell you it's your fault and they won't really care.

Interviewer: So even though the girl sent an image, say to her boyfriend, totally consensual, they were in a relationship, they broke up and he sends it on, the girl would be blamed?

Lucy: It's still the girl's fault.

All:Yeah.

Donna: It’s always the girl's fault. (High School 1, girl’s focus group)

When Donna states 'it's always the girl's fault' she is not suggesting it is but rather highlights her recognition of the unfairness of structures requiring girls to be both sexually available and attractive yet simultaneously act to punish them if they transgress gendered norms. Donna suggests what has become normalised is young people's resignation to seek help and the blame they receive if they do. Currently, the attitudes of students who participated in the study appear to echo the dominant narratives and education programs teaching students not to send images in the first place. But these can be changed. Take for example the suggestions by the same group of girls:

Lucy: I think the boy should get taught from an early age, that this isn't right. To say what you shouldn't do [to a girl], plus the girl should know, because some girls who are like, that's what they need to do [sending nude images] because they feel sometimes worthless [...] so I feel like girls should get taught that, "you are actually something and you're worth so much more" and boys should be taught, "this isn't how you treat a girl” (High School 1, girl’s focus group).

If we are to follow Lucy's suggestion there are other ways. Schools can be places to challenge and places to empower. Current responses to abuse through image sharing have been individualised in nature. They have looked at individual incidents as failings by young people for sending the images in the first place and then for sharing them further. As such responses have focussed on individuals. They have sanctioned individuals. They have 
educated young people to not take photos of themselves. And they have spread the message it is easier to cast all sexting as harmful rather than recognise the importance of understanding abuse through sexual image sharing within a context of harm.

\section{Conclusion}

The focus of this article has been on current responses to abuse through sexual image sharing in schools. The mismatch between law and guidance on sexting raises significant challenges for schools. This challenge is augmented through staff perceptions and responses that conflate consensual image sharing with abuse through image sharing. While students could articulate the significance and implications of abuse through image sharing, school responses appeared aimed at targeting all forms of image sharing. Furthermore, schools felt unsure of how to manage incidents directly and what approaches work. Based on the evidence I have presented, in this final section I provide suggestions to support responses and highlight some future avenues for research. Schools are not solely responsible. External agencies have a key role to play and it is vital that relationships are established and maintained across schools and within local multi-agency partnerships. I suggested at the beginning that schools both need responses and have responsibility. In order to address the product of inaction and create responses that address harmful image sharing schools would need:

- Robust tried and tested guidance on how to respond to abuse through sexual image sharing as opposed to responses that conflate consensual and non-consensual sharing;

- Appropriately resourced and funded external organisations that are able to provide specialist support and advice when school environments enable abuse through sharing;

- Support to develop digital competency in staff to understand advancements in technology including tools and mechanisms to tackle online abuse. 
At the same time, schools have a responsibility for changing the social conditions in which sending images becomes abusive. This would need:

- Education to young people that focusses on preventing abuse through image sharing of images and recognises the gendered power dynamics inherent within sexting;

- Harmful incidents to be responded to in ways that are perceived to be impactful by young people, and;

- Environments that support young people rather than shame them if photos are shared without consent.

Schools face many challenges in responding to the culture around abuse through image sharing but they also have many unique opportunities. While this research has focussed on abuse through image sharing within a British context these challenges are not unique to the UK. There are many opportunities for the evidence presented here to contribute to international discussions in this area. For example, work from the US on bystander interventions could provide future avenues to develop school approaches to tackling sexual harm in schools (Polanin, Espelage, and Pigott 2012). Furthermore, while research has explored young people's experiences of abuse through image sharing, few studies have engaged with those involved in the non-consensual sharing of images. More research is needed which engages with young people that have experienced or have been involved in the harmful sharing of images, what the impacts are and how this can be responded to.

To respond to abusive and harmful uses of sexual images school must first differentiate between consensual and non-consensual images. This requires working with young people to understand how they use technology to communicate and develop sexually in a digital age. By working together, educators, young people, policymakers, practitioners and researchers 
have the opportunity to challengethe harmful cultures that enable abuse through image sharing.

\section{Acknowledgements}

I would like to thank all the participants that contributed to this research and the input and advice of the research team, Carlene Firmin and Joanne Walker. Thanks also to the two anonymous reviewers and Zoë Croom.

\section{References}

Albury, Kath, and Kate Crawford. 2012. "Sexting, consent and young people's ethics: Beyond Megan's Story." Continuum no. 26 (3):463-473.

Angelides, Steven. 2013. "'Technology, hormones, and stupidity’: The affective politics of teenage sexting." Sexualities no. 16 (5-6):665-689.

Barbovschi, Monica, and Anca Velicu. 2015. "“Fraped” Selves: Hacked, Tagged, and Shared Without Permission. The Challenges of Identity Development for Young People on Facebook." LIVING IN THE DIGITAL AGE:15.

Branch, Kathryn, Carly M Hilinski-Rosick, Emily Johnson, and Gabriela Solano. 2017. "Revenge porn victimization of college students in the United States: An exploratory analysis." International Journal of Cyber Criminology no. 11 (1):128-142.

Calvert, Clay. 2009. "Sex, cell phones, privacy, and the first amendment: when children become child pornographers and the Lolita Effect undermines the law." CommLaw Conspectus no. 18:1.

Chalfen, Richard. 2009. "'It's only a picture’: Sexting, 'smutty’snapshots and felony charges." Visual Studies no. 24 (3):258-268.

Charteris, Jennifer, Sue Gregory, and Yvonne Masters. 2016. "'Snapchat’, youth subjectivities and sexuality: disappearing media and the discourse of youth innocence." Gender and Education:1-17.

Cooper, Karen, Ethel Quayle, Linda Jonsson, and Carl Göran Svedin. 2016. "Adolescents and self-taken sexual images: A review of the literature." Computers in human behavior no. 55:706-716.

Crenshaw, Kimberle. 1997. "Intersectionality and identity politics: Learning from violence against women of color."

Crimmins, Danielle M, and Kathryn C Seigfried-Spellar. 2014. "Peer attachment, sexual experiences, and risky online behaviors as predictors of sexting behaviors among undergraduate students." Computers in Human Behavior no. 32:268-275.

Department for Education. 2018. Keeping Children Safe in Education staturotry guidance for schools and colleges. London: Crown Copyright.

Dobson, Amy Shields, and Jessica Ringrose. 2016. "Sext education: pedagogies of sex, gender and shame in the schoolyards of Tagged and Exposed." Sex Education no. 16 (1):8-21. 
Döring, Nicola. 2014. "Consensual sexting among adolescents: Risk prevention through abstinence education or safer sexting?" Cyberpsychology: Journal of Psychosocial Research on Cyberspace no. 8 (1).

Draper, Nora R. A. 2012. "Is Your Teen at Risk? Discourses of adolescent sexting in United States television news." Journal of Children and Media no. 6 (2):221-236. doi: 10.1080/17482798.2011.587147.

Englander, Elizabeth. 2012. "Low risk associated with most teenage sexting: A study of 617 18-year-olds."

Firmin, C. 2017a. Abuse between Young People: A Contextual Account. Oxon: Routledge.

Firmin, Carlene. 2017b. "Contextualizing case reviews: A methodology for developing systemic safeguarding practices." Child \& Family Social Work.

Gov.uk. Racist Incidents 2010 [cited 04 May 2018. Available from https://assets.publishing.service.gov.uk/government/uploads/system/uploads/attachme nt_data/file/339089/Racist_Incident_Reporting_October_2010_1_.doc.

Gross, Matt. 2017. "Cyber sexual bullying,"sexting” in schools, and the growing need to educate the youth." The University of the Pacific Law Review no. 48 (3):555-574.

Hackett, Simon. 2010. "Children, young people and sexual violence." In Children behaving badly?: peer violence between children and young people, edited by Christine Barter and David Berridge. London: John Wiley \& Sons.

Harvey, Laura, and Jessica Ringrose. 2015. "Sexting, ratings and (Mis) Recognition: Teen boys performing classed and racialized masculinities in digitally networked publics." In Children, Sexuality and Sexualization, 352-367. Springer.

Hasinoff, Amy Adele. 2013. "Sexting as media production: Rethinking social media and sexuality." New Media \& Society no. 15 (4):449-465.

Holoyda, Brian, Jacqueline Landess, Renee Sorrentino, and Susan Hatters Friedman. 2018. "Trouble at teens' fingertips: Youth sexting and the law." Behavioral sciences \& the law.

Karaian, Lara, and Katherine Van Meyl. 2015. "Reframing risque/risky: Queer temporalities, teenage sexting, and freedom of expression." Laws no. 4 (1):18-36.

Krueger, Patricia. 2010. "It's not just a method! The epistemic and political work of young people's lifeworlds at the school-prison nexus." Race Ethnicity and Education no. 13 (3):383-408.

Levine, Deb. 2013. "Sexting: a terrifying health risk... or the new normal for young adults?" Journal of Adolescent Health no. 52 (3):257-258.

Moran-Ellis, J. 2011. "Sexting, Intimacy and Criminal Acts: Translating Teenage Sexualities." In Policing Sex, edited by P. Johnson and D. Dalton, 115-132. London: Routledge.

NPCC. 2016. Briefing note: Police action in response to youth produced sexual imagery ('Sexting').

O'Connor, Kimberly, Michelle Drouin, Nicholas Yergens, and Genni Newsham. 2017. "Sexting Legislation in the United States and Abroad: A Call for Uniformity." International Journal of Cyber Criminology no. 11 (2):218-245.

Paul, S. 2017. "Why your child could go to prison for ten years for 'sexting' on their phone " Daily Mail.

Phippen, Andy. 2009. Sharing personal images and videos among young people. In Southwest Grid for Learning, Nov. University of Plymouth.

Polanin, Joshua R, Dorothy L Espelage, and Therese D Pigott. 2012. "A meta-analysis of school-based bullying prevention programs' effects on bystander intervention behavior." School Psychology Review no. 41 (1):47. 
Quayle, Ethel, and Karen Cooper. 2015. "The role of child sexual abuse images in coercive and non-coercive relationships with adolescents: A thematic review of the literature." Child \& Youth Services no. 36 (4):312-328.

Ringrose, Jessica, Laura Harvey, Rosalind Gill, and Sonia Livingstone. 2013. "Teen girls, sexual double standards and 'sexting': Gendered value in digital image exchange." Feminist Theory no. 14 (3):305-323.

Salter, Michael, Thomas Crofts, and Murray Lee. 2012. "Beyond criminalisation and responsibilisation: Sexting, gender and young people." Current Issues Crim. Just. no. 24:301.

Simpson, Brian. 2013. "Challenging childhood, challenging children: Children's rights and sexting." Sexualities no. 16 (5-6):690-709.

Smith, Peter K, Fran Thompson, and Julia Davidson. 2014. "Cyber safety for adolescent girls: bullying, harassment, sexting, pornography, and solicitation." Current opinion in obstetrics and gynecology no. 26 (5):360-365.

Steeves, V. 2014. Young Canadians in a Wired World, Pase III: Sexuality and Romantic Relationships in the Digital Age. . edited by MediaSmarts. Ottawa.

Stroud, Scott R. 2014. "The dark side of the online self: A pragmatist critique of the growing plague of revenge porn." Journal of Mass Media Ethics no. 29 (3):168-183.

Temple, Jeff R, and Yu Lu. 2018. "Sexting from a Health Perspective: Sexting, Health, and Risky Sexual Behaviour." In Sexting, 53-61. Springer.

The National Campaign to Prevent Teen and Unplanned Pregnancy. 2008. Sex and Tech: Results from a Survey of Teens and Young Adults. Washington: DC.

Think U Know. Exposed 2017 [cited 29 September 2017. Available from https://www.thinkuknow.co.uk/14_plus/Films/Exposed/.

ThinkUKnow. Exposed 2011 [cited 25 April 2018. Available from https://www.thinkuknow.co.uk/professionals/resources/exposed/.

UKCCIS. 2016. Sexting in schools and colleges: Responding to incidents and safeguarding young people. UK Council for Child Internet Safety.

Van Ouytsel, Joris, Ellen Van Gool, Koen Ponnet, and Michel Walrave. 2014. "Brief report: The association between adolescents' characteristics and engagement in sexting." Journal of adolescence no. 37 (8):1387-1391.

Van Ouytsel, Joris, Michel Walrave, and Ellen Van Gool. 2014. "Sexting: Between thrill and fear-How schools can respond." The Clearing House: A Journal of Educational Strategies, Issues and Ideas no. 87 (5):204-212.

Willard, Nancy. 2010. "Sexting and youth: Achieving a rational response." Journal of Social Sciences no. 6 (4):542-562.

Williams, Jamie L. 2011. "Teens, Sexts \& Cyberspace: The Constitutional Implications of Current Sexting \& Cyberbullying Laws." Wm. \& Mary Bill Rts. J. no. 20:1017.

Wolak, Janis, and David Finkelhor. 2011. Sexting: A typology, Crimes against Children Research Center. Durham:DH. 